\title{
The impact of departmental interdependencies and management accounting system use on subunit performance: A comment
}

\section{Frank G. H. Hartmann}

To cite this article: Frank G. H. Hartmann (2005) The impact of departmental interdependencies and management accounting system use on subunit performance: A comment, European Accounting Review, 14:2, 329-334, DOI: 10.1080/09638180500043527

To link to this article: https://doi.org/10.1080/09638180500043527

曲 Published online: 17 Feb 2007.

Submit your article to this journal $\llbracket$

Џ Article views: 154

Q View related articles $\sqsubset$

Citing articles: 10 View citing articles 5 


\title{
The Impact of Departmental Interdependencies and Management Accounting System Use on Subunit Performance: A Comment
}

\author{
FRANK G. H. HARTMANN \\ Rotterdam School of Management, Erasmus University, the Netherlands
}

The paper 'The Impact of Departmental Interdependencies and Management Accounting System Use on Subunit Performance' by Jonas Gerdin (this issue) provides a typical and excellent example of an empirical study that solidly roots in the contingency paradigm in management accounting system (MAS) research. Studies in this paradigm attempt to explain MAS design or MAS use, by arguing and demonstrating its optimality or 'fit' within the environmental context in which it operates. The management accounting contingency paradigm is not unproblematic, as recent reviews have amply illustrated. Generally, reviews have critically addressed the theoretical content of this paradigm, and have questioned its overall achievement (see, e.g. Chapman, 1997; Hartmann, 2000; Chenhall, 2003). Specifically, reviews have critically evaluated the paradigmatic conceptualisation and measurement of the contingency fit conditions sought and found, especially within the typical cross-sectional methodology that the studies apply (Hartmann and Moers, 1999, 2003; Luft and Shields, 2003; Gerdin and Greve, 2004). These latter reviews have yielded several important imperatives for MAS contingency research, of which two are of specific interest to this commentary. First, the reviews establish that since there are several alternative conceptualisations of

Correspondence Address: Frank G. H. Hartmann, Erasmus University, Rotterdam School of Management, PO Box 1738, 3000 DR Rotterdam, the Netherlands. E-mail: f.hartmann@rsm.nl 
'fit' conditions of MAS, which means that there are various ways in which a MAS may 'fit' the context in which it operates, the demonstration of 'fit' as such is not very telling (cf. Otley, 1980, p. 414; Hartmann and Moers, 1999, p. 309). This implies that studies should be careful in developing and testing contingency hypotheses. Second, the reviews sharply delineate the so-called selection concept of 'fit' from the interaction concept of 'fit', arguing strongly for their theoretical incompatibility (Luft and Shields, 2003). ${ }^{1}$ According to the selection concept of 'fit', MAS design or use is predicted and explained as a response to the MAS context. Typically, these studies thus seek causal relationships between contextual variables (such as interdependence in this study) and MAS design or use. The causality of the interdependence-MAS relationship is theoretically argued to root in an optimisation process (selection process) that results in MAS-context 'fit'. Substantively, this means that organisations are theoretically expected to - and empirically shown to - select their MAS design or use to 'fit' their level of interdependence. The latter necessitates an empirical demonstration that MAS design or use shows theory-consistent, cross-sectional fluctuations with the contextual condition (e.g. interdependence) studied. According to this 'fit' concept, theory predicts optimisation through selection, and therefore theory does not predict performance differences. Any cross-sectional performance difference cannot be explained by the same theory that predicts differences in MAS design or use, and should be considered noise.

The interaction concept of 'fit' is fundamentally different, and almost the opposite of the selection concept of 'fit'. According to this concept, companies may, or may not, adapt their MAS to interdependence. The associated contingency theory predicts that certain interdependence-MAS combinations outperform others. According to this 'fit' concept, theory predicts performance differences, and therefore theory does not predict differences in MAS design or use. Any cross-sectional differences in MAS design or use cannot be explained by the same theory that predicts performance differences, and should be considered noise. The two models are displayed in Figure 1.

Gerdin (this issue) provides an insightful demonstration of the implications of the two imperatives mentioned above, and of some of the controversies in the extant MAS contingency literature surrounding the definition and measurement of 'fit'. The paper explicitly proposes a mediation model of fit (see Figure 1, Table C) to test the contextual fit of MAS. In the conceptual model, MAS mediates the relationship between interdependence and performance. The paper argues that it wants to explicitly investigate:

... the effect of an appropriate 'fit' between the degree of departmental interdependence and MAS use on subunit performance. The rationale is that [...] prior research has not shown that a proper match between these variables actually enhances subunit performance. Instead, socalled selection/congruence models [...] have been used where the MAS 
TABLE A

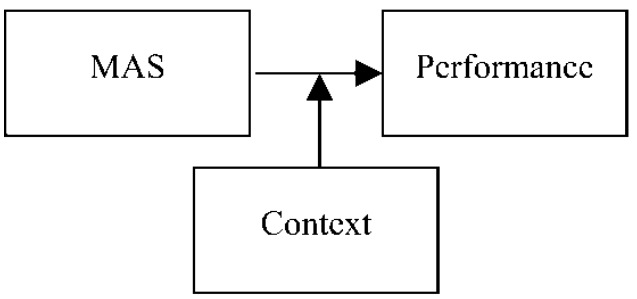

TABLE B

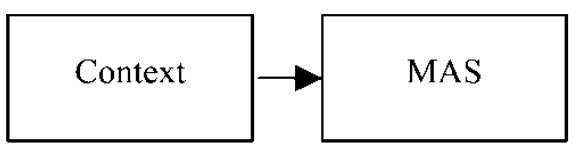

TABLE C

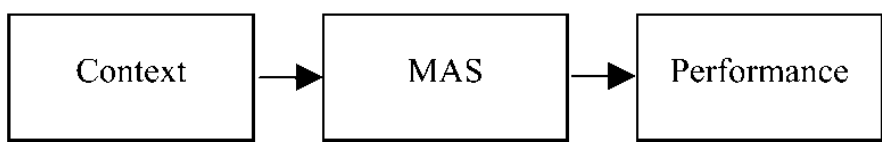

Figure 1. Interaction (Table A), selection (Table B) and 'mixed' (Table C) models of contingency 'fit'.

is the dependent variable and the primary task is to explore the nature of the relationships between the context and the MAS. However, the assumption that underlies all these studies - that an appropriate fit between these variables affects subunit performance - is never explicitly included in the research models and empirically tested.

(pp. 298-299)

This point of view is problematic. If one wants to assess whether the assumption holds that 'fit' between interdependence and MAS leads to superior performance, the only possible way is to analyse whether a 'misfit' between interdependence and MAS leads to inferior performance. ${ }^{2}$ To analyse these propositions, one needs to compare a situation of fit with a situation of misfit, but that 
simply means exploring an interaction between interdependence and MAS. ${ }^{3}$ In the theory section, Gerdin elaborates its general aim as follows:

In conclusion [...] it is reasonable to assume that there is a relationship between departmental interdependencies and MAS use and that a proper match between these two factors has a positive effect on subunit performance. Therefore, the relationship between the variables in question will be depicted in terms of a mediation model.

(pp. 302-303)

Here it is apparent that the paper attempts to mix the two (selection and interaction) forms of 'fit'. On the one hand, it predicts that the MAS will adapt to the level of interdependence (resulting in selection 'fit'). On the other hand, it also expects to detect performance effects, although these can only be attributable to the existence of selection 'misfit'. No single theory can predict both at the same time. In footnote 3 , Gerdin clarifies his position by arguing that:

... there are always organizations moving towards congruent (survival) positions and vice versa (cf. Donaldson, 2001). Accordingly, there is reason to believe that there, at any point of time, should be variations in performance as the result of varying degrees of fit between interdependence and MAS use also when the general expectation is that managers typically adapt their MAS use to the situation.

Differences in performance, therefore, are caused by 'varying degrees of fit', which in turn are caused by the fact that organisations are moving towards 'fit' situations and back. Although these observations are potentially true, and do provide a tough challenge for contingency theory at large, they provide little solace in this particular case. If performance differences are related to varying degrees of selection fit, we need theory to explain the causes of this variation, in addition to the theory that predicts the general (selection) trend. Without such additional theory, variation in the degree of fit constitutes random noise, which provides little ground for any subsequent explanation of performance differences. ${ }^{4}$

There is another, and perhaps more trivial, problem associated with the extension of the simple selection model (Figure 1, Table B) with a performance variable as is done in this study. Overall, the model now implies that interdependence results in performance (albeit through MAS). Substantively, this would mean that companies could boost their performance by increasing their level of internal interdependence. The opposite seems to be more truthful, since - all things being equal - more interdependence requires more costly alignment and coordination, which reduces performance. The model is plausible, if we consider it within the specific industry conditions that necessitate customisation (p. 1). In 
these industries, higher interdependence may be a necessary condition for higher performance. This, however, again points to an interaction effect. ${ }^{5}$

Finally, the tension between selection and interaction can be further illustrated by the secondary analysis performed in Section 6 of the paper. Here, Gerdin seeks to provide an explanation for the found weak relationship between amount of $M A S$ and performance for the whole sample, by assessing whether the relationship is similar for the two subgroups (high and low interdependence). He finds that the MAS-performance correlation is highest in the high-interdependence subgroup, which is interpreted as:

\section{... only managers experiencing higher levels of interdependence benefit}

from additional MAS information during task execution.

This indicates the existence of an interaction effect (strength) between interdependence and MAS (cf. Hartmann and Moers, 1999).

In sum, more attention is needed to the intricacies of contingency theory, if our aim is to merge selection and interaction approaches (see, e.g. Bisbe and Otley, 2004). Gerdin's paper provides an excellent first step in this direction, as it argues and demonstrates that 'in reality' MAS both adapts to context, and may explain performance differences through misfit with the context. Since, however, the current state of contingency theory supports both types of, what are in fact, incompatible predictions, there is a serious need for further elaboration of the contingency model in MAS research. Recent analyses, such as in Luft and Shields (2003), and in the conceptual work in Donaldson (2001), suggest that a more dynamic, processual view of contingency fit may be required to extend our knowledge as to why companies adapt their MAS to the environmental context, and in what pace, or why not. As this involves the study of dynamic processes, it is hard to see how this can be achieved within the cross-sectional methodology that is typical for MAS research. ${ }^{6}$

\section{Notes}

${ }^{1}$ The literature has used different labels for these two kinds of 'fit'. For example, the interaction concept of 'fit' may also be labelled the moderation concept of 'fit'; the selection concept of 'fit' could also be called the adaptation or congruence concept of 'fit' (see also, e.g. Hartmann and Moers, 1999; Luft and Shields, 2003).

${ }^{2}$ Alternatively, one could argue that since the selection concept of 'fit' does not rest on a (testable) assumption of optimisation, but constitutes an (untestable) axiom, any testing whether selection fit results in superior performance is futile.

${ }^{3}$ This seems the backside of the paradox, associated with the use of moderation models, between the ex ante assumption that managers do not adjust their MAS use to departmental interdependencies and the ex post assumption that they should (cf. Hartmann and Moers, 2003). Note that the objections raised in this comment are based on the fact that cross-sectional (rather than longitudinal) performance is the object of explanation. 
${ }^{4}$ An interesting avenue is to explore differences in speed of adapting MAS to the context. If such differences in speed are predicted to be caused by context as well, the appropriate selection model would include a context $\times$ context interaction.

${ }^{5} \mathrm{H} 3$ attempts to establish that performance is no direct result of interdependence. The corroboration of $\mathrm{H} 3$ only illustrates that companies with higher interdependence, all adapt their MAS in the same direction. This provides additional support for the existence of selection fit.

${ }^{6}$ Note that the difficulty of comparing selection and interaction models is not restricted to the area of MAS research. In the psychology literature there is much debate about the possibilities and impossibilities of matching mediation and moderation models (see, e.g. Holmbeck, 1997; Shrout and Bolger, 2002), and strong pleas to test mediation models through moderation statistics (see, e.g. MacKinnon et al., 2002). Note, however, that in this literature many constructs involved are traits, rather than variables, which hinders comparison with MAS-related contingency work, and that studies more often rely on longitudinal data (see, e.g. Marjoribanks, 2003, who combines mediation and moderation elements in one causal model, using longitudinal and cross-sectional data).

\section{References}

Bisbe, J. and Otley, D. (2004) The effects of the interactive use of management control systems on product innovation, Accounting, Organizations and Society, 29, pp. 709-737.

Chapman, C. S. (1997) Reflections on a contingency view of accounting, Accounting, Organizations and Society, 22, pp. 189-205.

Chenhall, R. H. (2003) Management control systems design within its organizational context: findings from contingency-based research and directions for the future, Accounting, Organizations and Society, 28, pp. 127-168.

Donaldson, L. (2001) The Contingency Theory of Organizations (Thousands Oaks, CA: Sage).

Gerdin, J. and Greve, J. (2004) Forms of contingency fit in management accounting research - a critical review, Accounting, Organizations and Society, 29(3/4), pp. 303-326.

Hartmann, F. G. H. and Moers, F. (1999) Testing contingency hypotheses in budgetary research: an evaluation of the use of moderated regression analysis, Accounting, Organizations and Society, 24, pp. 291-315.

Hartmann, F. G. H. and Moers, F. (2003) Testing contingency hypotheses in budgetary research using moderated regression analysis: a second look, Accounting, Organizations and Society, 28, pp. $185-191$.

Holmbeck, G. N. (1997) Toward terminological, conceptual, and statistical clarity in the study of mediators and moderators: examples from the child-clinical and pediatric psychology literatures, Journal of Consulting and Clinical Psychology, 65, pp. 599-610.

Luft, J. and Shields, M. D. (2003) Mapping management accounting: graphics and guidelines for theory-consistent empirical research, Accounting, Organizations and Society, 28, pp. 169-249.

MacKinnon, D. P., Lockwood, C. M., Hoffman, J. M., West, S. G. and Sheets, V. (2002) A comparison of methods to test mediation and other intervening variable effects, Psychological Methods, 7 , pp. 83-104.

Marjoribanks, K. (2003) Learning environments, family contexts, educational aspirations and attainment: a moderation-mediation model extended, Learning Environments Research, 6, pp. $247-265$.

Otley, D. (1980) The contingency theory of management accounting: achievement and prognosis, Accounting, Organizations and Society, 5, pp. 413-428.

Shrout, P. E. and Bolger, N. (2002) Mediation in experimental and nonexperimental studies: new procedures and recommendations, Psychological Methods, 7, pp. 422-445. 